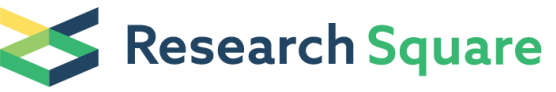 \\ Preprints are preliminary reports that have not undergone peer review. \\ They should not be considered conclusive, used to inform clinical practice, or referenced by the media as validated information.
}

\section{A suspected case of SARS-CoV-2 persistence with reactivation}

Derly Andrade Molina ( $\square$ dmandrademolina@uees.edu.ec)

Omics Sciences Laboratory, Faculty of Medical Sciences, Universidad Espíritu Santo https://orcid.org/0000-0002-2651-5884

Juan Fernández-Cadena

Omics Sciences Laboratory, Faculty of Medical Sciences, Universidad Espíritu Santo

Telmo Fernández-Cadena

COVID-19 Intensive Care Unit, Hospital Luis Vernaza

Paúl Cárdenas \& USFQ-COVID Consortium

Instituto de Microbiología, Universidad San Francisco de Quito

Gabriel Morey-León

Faculty of Medical Sciences, Universidad de Guayaquil

Rubén Armas-Gonzales

Faculty of Sciences, Escuela Superior Politécnica del Litoral

Darlyn Amaya-Márquez

Faculty of Sciences, Escuela Superior Politécnica del Litoral

Katheryn Sacheri-Viteri

Omics Sciences Laboratory, Faculty of Medical Sciences, Universidad Espíritu Santo

Ketty Cordova Falconi

Omics Sciences Laboratory, Faculty of Medical Sciences, Universidad Espíritu Santo

Fernando Espinoza Fuentes

Omics Sciences Laboratory, Faculty of Medical Sciences, Universidad Espíritu Santo

Jose Barberán

Omics Sciences Laboratory, Faculty of Medical Sciences, Universidad Espíritu Santo

Fernando Valiente-Echeverría

Universidad de Chile https://orcid.org/0000-0001-9156-2516

Ricardo Soto-Rifo

Molecular and Cellular Virology Laboratory, Virology Program, Institute of Biomedical Sciences, HIV/AIDS Workgroup, Universidad de Chile

Article

Keywords: SARS-CoV-2, Reinfections 
Posted Date: October 26th, 2020

DOl: https://doi.org/10.21203/rs.3.rs-92286/v1

License: (c) (i) This work is licensed under a Creative Commons Attribution 4.0 International License. Read Full License 


\section{Abstract}

Reinfections with SARS-CoV-2 have been verified by the presence of phylogenetically distant viruses in each episode. Here, we report a suspected case of SARS-CoV-2 persistence with reactivation in a 35-years old patient presenting positive RT-PCR on April 7th and August 7th, each episode characterized by mild and severe symptoms, respectively. Sequencing of viral genomes identified only two SNPs indicating the presence of genetically linked viruses for the first time. Subsequently to hospital discharge, the patient presented a positive diagnosis for SARS-CoV-2 in stool, urine and semen samples.

\section{Main Text}

The novel human coronavirus SARS-CoV-2 emerged in Wuhan, province of Hubei in China in December 2019, and since it has infected more than 37 million people worldwide and 1.079 .029 deaths (as of October 13th, 2020) ${ }^{1}$. In the absence of vaccines or any specific antiviral treatment, people depend on a protective immune response to fight against SARS-CoV-2 infection and the effects of COVID-192, 3 . In addition to the new outbreaks occurring in places with previously controlled infections, cases of reinfections have also been reported in patients from Hong Kong ${ }^{4}$, Belgium and Ecuador ${ }^{5}$ as well as in health workers from Nevada and India and are expected to accumulate during the following months 4, 5, 6, 7,8 . A hallmark of these cases is phylogenetically distant viruses in samples from both events, which indicate that a new infection and no persistence of the original virus occurred. Here, we report a suspected case of SARS-CoV-2 persistence with reactivation in a healthcare worker at the Teodoro Maldonado Carbo Hospital in Guayaquil, Ecuador.

The patient corresponds to a 35-years old medical doctor diagnosed with SARS-CoV-2 confirmed by RTPCR on April 7th (Fig. 1 and Table 1). This first episode was characterized by fever $\left(37.7^{\circ} \mathrm{C}-37.6^{\circ} \mathrm{C}\right)$, sneezing, nasal obstruction and dry cough. Lung CT scan was normal. No evidence of anti-SARS-CoV-2 IgG/IgM was detected on April 15th and April 22nd by lateral flow test (Fig. 1 and Table 1). Moreover, RTPCR from a nasopharyngeal swab sample performed on April 17th was negative. Given the mild symptoms and the negative RT-PCR, the patient resumed his activities at the hospital ten days following diagnosis.

On August 4th (i.e., 119 days after the first episode and being asymptomatic during that period of time), the patient presented general malaise, weakness and fever $\left(38.5^{\circ} \mathrm{C}\right)$, which reached $39^{\circ} \mathrm{C}$ on August 5 th. A Lung CT scan showed diffuse ground glass lung patterns in basal and middle basal fields suggestive of COVID-19. The patient received treatment with azithromycin $500 \mathrm{mg}$ QD, acetylsalicylic acid $100 \mathrm{mg}$ QD, nitazoxanide $500 \mathrm{mg}$ QD, paracetamol $1 \mathrm{gr} \mathrm{PRN}$ and Enoxaparin $60 \mathrm{mg} \mathrm{SC}$. On August 6th and 7th, the patient presented arthralgia, myalgia and fever. Confirmatory RT-PCR was performed on August 7th (Fig. 1 and Table 1). On August 8th, the patient presented dry cough and dyspnea on great exertion and on August 9th, the fever raised to $39.9^{\circ} \mathrm{C}$, not responding to intramuscular or intravenous antipyretics. The patient was admitted to the hospital where an oxygen cannula was placed. A Lung CT scan carried out on August 10th showed pulmonary consolidations and atelectasis bands. Treatment with 
corticosteroid and broad-spectrum antibiotics (Imipenem $500 \mathrm{mg}$ ) were started, and the patient was changed to an oxygen face mask. On August 11th, the patient was transferred to Hospital Luis Vernaza in Guayaquil with severe respiratory failure (Fig. 2A). High flow oxygen cannula was required to maintain proper oxygenation. Antibiotic treatment with meropenem and vancomycin was started. Furthermore, a single-dose of Tocilizumab was prescribed due to high levels of circulating IL-6, ferritin and C- Reactive protein, inflammation biomarkers that continued high until September (Table 1). At 48 hours after admission, blood cultures revealed the presence of $S$. aureus. The patient was transfused with convalescent plasma. Worsening of the respiratory condition led to orotracheal intubation for assisted ventilation on August 13th, at this point clinical evidence of status epilepticus was present with tonic clinic convulsive manifestations. A cerebral magnetic resonance imaging (MRI) was performed and results show evidence of limbic encephalitis (Fig. 2B), which is related to encephalitis neuroimaging reported recently in COVID-19 patients 9,10 . The patient evolved favorably being discharged from the hospital on August 22nd. RT-PCR and IgG/IgM were positive on September 4th. Finally, the patient presented a negative RT-PCR on October 5th (Fig. 1).

Since these mild and severe COVID-19 episodes occurred in the same patient with a 4-months delay where suggestive of reinfection, we performed SARS-CoV-2 whole-genome sequencing using the Oxford Nanopore ARTIC Network protocol for the two different infection episodes (samples 032 and 4477, respectively were stored at $-80^{\circ} \mathrm{C}$ ). Strikingly, we observed that the viral sequence obtained from the second episode was highly similar to the sample obtained on April 7th, only presenting two SNPs (Fig. 3A). As such, phylogenetic analysis of the viral sequences revealed that both viruses are genetically linked being classified together into the B.1.1 lineage, clade GR suggesting the persistence of the original variant (Fig. 3B). A SARS-CoV-2 whole-genome sequence obtained from a health worker colleague also diagnosed on April 7th was near identical in sequence to the suspected case of persistence, while other SARS-CoV-2 sequence obtained from a second colleague partner diagnosed the same day was assigned to clade G, lineage B.1 (Fig. 3B). We also looked at the presence of viral RNA in nasopharyngeal swabs, saliva, urine, stool, blood and semen samples of the suspected case detecting viral genetic material in urine, stool and semen, suggesting viral persistence in this patient (Table 1).

Immunity against SARS-CoV-2 in the population is a major concern for the management of the COVID-19 pandemic. A recent study showed that the presence of antibodies against seasonal human coronaviruses is rather short-lasting ${ }^{11}$. Also, several studies performed in Europe have shown that the presence of antiSARS-CoV-2 antibodies ranged between 0 and $42.2 \%$ in the general population ${ }^{12}$. On the other hand, studies have shown that SARS-CoV-2 can elicit specific CD $4+$ and CD $8+$ T-cells responses in individuals exposed to the virus ${ }^{13,14,15}$. Interestingly, these studies showed an important presence of T-cell responses in unexposed and seronegative individuals attributed to cross-reactivity with seasonal coronaviruses. One of these reports also showed the presence of long-lasting CD $4+$ and CD8 + T-cells from individuals exposed to SARS-CoV in 2003 , suggesting that T-cell immunity against SARS-CoV-2 should be long-lasting ${ }^{13}$. Under this scenario, cases of reinfections with genetically distant viruses have been reported at least in Hong Kong, Belgium, India, USA and Ecuador. While some of these new 
infections were milder than the first episode, some of them resulted in a severe manifestation of the disease requiring mechanical ventilation. The case presented here represents a warning for the possibility of viral persistence and reactivation in individuals exposed to SARS-CoV-2, which should be considered as a potential risk when assessing policies related to viral resolution and transmission pathways. The results show the possible persistence in the testicles and urinary tract and faeces, suggesting the possibility of sexual transmission and transmit via the orofecal route or in contrast, SARS-CoV-2 could be shed and eliminated by the gastrointestinal tract. However, studies are lacking to verify whether it can remain viable and infectious in faecal, urine and semen samples. The possibility that SARS-CoV-2 could persist in testis and be sexually transmitted is a major concern. In this study, samples were obtained a week after the patient was discharged from the hospital while he was severely affected by his second episode of COVID-19. To date, presence of SARS-CoV-2 in seminal fluid has been investigated in men with positive nasopharyngeal swabs and who still symptoms even $2-3$ days of before semen collected ${ }^{16,17}$. In other studies, semen samples diagnosed as negative for SARS-CoV-2 were obtained before the development of symptoms or after developing symptomatology $18,19,20$. Furthermore, patients with severe COVID-19 symptomatology were excluded from the analysis and only included patients with mild to moderate symptoms ${ }^{21}$. It has been proven that some viruses are not able to replicate in the male reproductive system, but testis correspond to an immunoprivileged site with a favorable environment for the virus to escape from the host's immune system, rendering testis a potential site for the establishment

of a viral reservoir ${ }^{22}$. Indeed, testis could be a reliable potential viral reservoir site for SARS-CoV-2 due to the high expression levels of ACE2 in spermatogonia, Leydig and Sertoli cells ${ }^{23,24}$. Therefore, further studies are essential to determine the presence of SARS-CoV-2 in the semen including patients with severe COVID-19, re-infection and viral persistence.

\section{Materials And Methods}

Sample from the suspected patient was collected and codified from April 7th (first episode), August 7th (second episode, mild and severe symptoms), September 4th, September 11th and October 05th 2020, in a certified laboratory of the Espiritu Santo University. Ethical approval of this work was given by CEISHUSFQ (Comité de ética de investigación en seres humanos-USFQ): IE-JP067-2020-CEISH-USFQ. Nasopharyngeal swabs preserved in 400 ul of 1X DNA/RNA Shield ${ }^{\text {TM }}$ solution (Zymo Research, USA), saliva, urine, blood and semen samples were used for RNA extraction by Quick RNA viral kit (Zymo Research, CA, USA) according to the manufacturer's protocol in a biosafety type II chamber with HEPA filters. The RNA extracted was screened for the presence of SARS-CoV-2 by reverse transcriptase quantitative PCR (RT-qPCR) using Allplex ${ }^{\text {TM }}$ SARS-CoV-2 Assay a multiplex real-time PCR assay to detect 4 target genes (E, N RdRp and S gene) for asses the SARS-CoV-2 infection (Seegene Inc, CA, USA).

RNA from the respiratory sample from the suspected patient and colleagues working in the same field, which were diagnosed simultaneously on April 7th were prepared for MinION sequencing protocol. Primer Scheme approach developed by the ARTIC Network for nCoV- $2019^{25}$ using the V3 primer sets to generate an amplicon tiling path across the viral genome. cDNA MinION library preparation was performed using 
the Rapid 158 Barcoding kit (SQK-RBK004) following manufacturer instructions and then loaded into a MinION flow cell (FLO-MIN 106). Base calling of FAST5 files was performed using Guppy (version 3.4.5) ${ }^{26}$, and the RAMPART software (v1.0.5) from the ARTIC Network (https://github.com/articnetwork/rampart) was used to monitor sequencing in real-time. Sequence quality scoring, demultiplexing and adapter removal was performed with the NanoPlot and Porechop algorithms respectively ${ }^{27}$. The ARTIC Network bioinformatics pipeline was used for variant calling, and the reads were 165 mapped against the reference strain Wuhan-Hu-1 (GenBank accession number MN908947), to generate consensus genomes. The genomes were uploaded to the GISAID platform and NextStrain.org to determine the epidemiological linkage of circulating SARS-CoV-2 variants (Sequence ID: Sample 032: EPI_ISL_527819; Sample 4477: EPI_ISL_527818; Sample 128: EPI_ISL_491933; Sample 129: EPI_ISL_491934).

In order to determine the clade and lineage of the sequenced genomes, they were aligned with another 100 SARS-CoV-2 genomes obtained from GISAID ${ }^{28}$. Genomes were aligned via MAFFT v7.4 ${ }^{29}$ and phylogenetic reconstruction was performed by maximum likelihood via IQTREE v1.6 ${ }^{30}$ and the results were visualized using Dendroscope ${ }^{31}$.

\section{Declarations}

\section{Acknowledgements}

This work has been supported by the Centro de Investigaciones, Universidad Espíritu Santo, and by Iniciativa Sumar juntos-Banco Pichincha.

USFQ-COVID-19 Consortium: Belén Prado-Vivar ${ }^{1,2}$, Mónica Becerra-Wong $^{1}$, Juan José Guadalupe ${ }^{4}$, Sully Márquez ${ }^{1}$, Bernardo Gutierrez ${ }^{4,5}$, Michelle Grunauer ${ }^{3}$, Gabriel Trueba ${ }^{1}$, Patricio Rojas-Silva ${ }^{1}$, Verónica Barragán ${ }^{1}$, Paúl Cárdenas ${ }^{1,2}$

${ }^{1}$ Universidad San Francisco de Quito, COCIBA, Instituto de Microbiología

2Universidad San Francisco de Quito, Centro de Bioinformática

${ }^{3}$ Universidad San Francisco de Quito, Escuela de Medicina

${ }^{4}$ Universidad San Francisco de Quito, COCIBA, Laboratorio de Biotecnología Vegetal

${ }^{5}$ University of Oxford, Department of Zoology

\section{References}

1. WHO. WHO coronavirus disease (COVID-19) dashboard. https://covid19. who.int/ Date accessed: October 13, 2020 
2. Azkur, AK, Akdis, M, Azkur, D, et al. Immune response to SARS-CoV-2 and mechanisms of immunopathological changes in COVID 19. Allergy. 75: 1564-1581 (2020). https://doi.org/10.1111/all.14364

3. García, L. Immune Response, Inflammation, and the Clinical Spectrum of COVID-19. Front. Immunol.,11: 4-8 (2020) Available from: https://doi.org/10.3389/fimmu.2020.01441

4. To KK-W, Hung IF-N, Ip JD, Chu AW-H, Chan W-M, Tam AR, et al. Coronavirus Disease 2019 (COVID19) Re-infection by a Phylogenetically Distinct Severe Acute Respiratory Syndrome Coronavirus 2 Strain Confirmed by Whole Genome Sequencing. Clin Infect Dis. ciaa1275. (2020); Available from: https://doi.org/10.1093/cid/ciaa1275

5. Prado-Vivar B, Becerra-Wong M, Guadalupe JJ, Marquez S, Gutierrez B, Rojas-Silva P, et al. COVID-19 Re-Infection by a Phylogenetically Distinct SARS-CoV-2 Variant, First Confirmed Event in South America. SSRN Electron J. (2020); Available from: http://dx.doi.org/10.2139/ssrn.3686174

6. Gupta V, Bhoyar RC, Jain A, Srivastava S, Upadhayay R, Imran M, et al. Asymptomatic reinfection in two healthcare workers from India with genetically distinct SARS-CoV-2. Clin Infect Dis ciaa1451. (2020); Available from: https://doi.org/10.1093/cid/ciaa1451

7. Van Elslande J, Vermeersch P, Vandervoort K, Wawina-Bokalanga T, Vanmechelen B, Wollants E, et al. Symptomatic SARS-CoV-2 reinfection by a phylogenetically distinct strain. Clin Infect Dis ciaa1330. (2020); Available from: https://doi.org/10.1093/cid/ciaa1330

8. Tillett R, Sevinsky J, Hartley P, Kerwin H, Crawford N, Gorzalski A, et al. Genomic Evidence for a Case of Reinfection with SARS-CoV-2. SSRN Electron J. (2020); Avaiable from: https://papers.ssrn.com/sol3/papers.cfm?abstract_id=3680955

9. Kandemirli SG, Dogan L, Sarikaya ZT, Kara S, Akinci C, Kaya D, et al. Brain MRI Findings in Patients in the Intensive Care Unit with COVID-19 Infection. Radiology 8;297(1):E232-5. (2020). Available from: https://doi.org/10.1148/radiol.2020201697

10. Kihira S, Delman BN, Belani P, Stein L, Aggarwal A, Rigney B, et al. Imaging Features of Acute Encephalopathy in Patients with COVID-19: A Case Series. Am J Neuroradiol;41(10):1804 LP-1808. (2020). Available from: http://www.ajnr.org/content/41/10/1804.abstract

11. Edridge AWD, Kaczorowska J, Hoste ACR, Bakker M, Klein M, Loens K, et al. Seasonal coronavirus protective immunity is short-lasting. Nat Med. 2020; Available from:

http://dx.doi.org/10.1038/s41591-020-1083-1

12. European Centre for Disease Prevention and Control (ECDC). Immune responses and immunity to SARS-CoV-2 [12th October 2020]. Available from: https://www.ecdc.europa.eu/en/covid-19/latestevidence/immune-responses

13. Le Bert N, Tan AT, Kunasegaran $K$, Tham CYL, Hafezi M, Chia A, et al. SARS-CoV-2-specific T cell immunity in cases of COVID-19 and SARS, and uninfected controls. Nature,584(7821):457-62. (2020). Available from: http://dx.doi.org/10.1038/s41586-020-2550-z

14. Sekine T, Perez-Potti A, Rivera-Ballesteros O, Strålin K, Gorin J-B, Olsson A, et al. Robust T Cell Immunity in Convalescent Individuals with Asymptomatic or Mild COVID-19. Cell; 1;183(1):158- 
168.e14. (2020). Available from: https://doi.org/10.1016/j.cell.2020.08.017

15. Ong EZ, Chan YFZ, Leong WY, Lee NMY, Kalimuddin S, Haja Mohideen SM, et al. A Dynamic Immune Response Shapes COVID-19 Progression. Cell Host Microbe 10;27(6):879-882.e2. (2020). Available from: https://doi.org/10.1016/j.chom.2020.03.021

16. Li D., Jin M., Bao P., Zhao W., Zhang S. Clinical characteristics and results of semen tests among men with coronavirus disease 2019. JAMA Netw Open. 3(5):e208292 (2020); Available from doi:10.1001/jamanetworkopen.2020.8292.

17. Fan C, Li K, Ding Y, Lu WL, Wang J. ACE2 Expression in Kidney and Testis May Cause Kidney and Testis Damage After 2019-nCoV Infection. medRxiv. (2020); 2020.02.12.20022418. Available from: http://medrxiv.org/content/early/2020/02/13/2020.02.12.20022418.abstract

18. Holtmann N, Edimiris P, Andree M, Doehmen C, Baston-Buest D, Adams $\mathrm{O}$, et al. Assessment of SARSCoV-2 in human semen-a cohort study. Fertil Steril [Internet]. 2020;114(2):233-8. Available from: http://www.sciencedirect.com/science/article/pii/S0015028220305197

19. Paoli, D., Pallotti, F., Colangelo, S. et al. Study of SARS-CoV-2 in semen and urine samples of a volunteer with positive naso-pharyngeal swab. J Endocrinol Invest (2020); Available from: https://doi.org/10.1007/s40618-020-01261-1

20. Guo, L, Zhao, S, Li, W, et al. Absence of SARS-CoV-2 in semen of a COVID-19 patient cohort. Andrology. 00: 1- 6, (2020); Available from: https://doi.org/10.1111/andr.12848

21. Kayaaslan B, Korukluoglu G, Hasanoglu I, Kalem AK, Eser F, Akinci E, et al. Investigation of SARSCoV-2 in Semen of Patients in the Acute Stage of COVID-19 Infection. Urol Int, 104(9-10):678-83. 2020; Available from: https://www.karger.com/DOI/10.1159/000510531

22. Zhao, S., Zhu, W., Xue, S. et al. Testicular defense systems: immune privilege and innate immunity. Cell Mol Immuno/ 11, 428-437 (2014). Available from: https://doi.org/10.1038/cmi.2014.38

23. Wang Z, Xu X. scRNA-seq Profiling of Human Testes Reveals the Presence of ACE2 Receptor, a Target for SARS-CoV-2 Infection, in Spermatogonia, Leydig and Sertoli Cells, 9, (2020). Available from: https://www.preprints.org/manuscript/202002.0299/v1.

24. Fan C, Li K, Ding YH, et al. ACE2 Expression in Kidney and Testis May Cause Kidney and Testis Damage After 2019-nCoV Infection. Available from: https://www.medrxiv.org/content/10.1101/2020.02.12.20022418v1.

25. Quick J. nCoV-2019 sequencing protocol. 2020. Available from: https://www.protocols.io/view/ncov2019-sequencing-protocol-bbmuik6w/forks

26. Wick RR, Judd LM, Holt KE. Raw fast5s. Figshare. 2019. https://doi.org/10.26180/5c5a5fa08bbee.

27. De Coster W, D'Hert S, Schultz DT, Cruts M, Van Broeckhoven C. NanoPack: Visualizing and processing long-read sequencing data. Bioinformatics. 34(15), 2666-2669, (2018). Available from: https://doi.org/10.1093/bioinformatics/bty149

28. GISAID. Clade and lineage nomenclature aids in genomic epidemiology studies of active hCoV-19 viruses. Available at https://www.gisaid.org/references/ statements-clarifications/clade-and-lineagenomenclature-aids-in-genomicepidemiology-of-active-hcov-19-viruses/. Accessed 12 October 2020 
29. Katoh K, Standley DM. MAFFT multiple sequence alignment software version 7: improvements in performance and usability. Mol Biol Evol30:772-80. (2013); Available from: https://doi.org/10.1093/molbev/mst010

30. Nguyen L, Schmidt $H$, von Haeseler A, Minh BQ. IQ-TREE: a fast and effective stochastic algorithm for estimating maximum-likelihood phylogenies. Mol Biol Evol. Jan;32(1):268-74. (2015) Available from: doi: 10.1093/molbev/msu300. http://europepmc.org/abstract/MED/25371430

31. Daniel H. Huson and Celine Scornavacca. Dendroscope 3: An interactive tool for rooted phy-logenetic trees and networks, Systematic Biology (2012), http://sysbio.oxfordjournals.org/cgi/content/abstract/sys062? ijkey=ZCxPRbYt74aQJhR\&keytype=ref, software freely available from www.dendroscope.org

\section{Table}

\begin{tabular}{|c|c|c|c|c|c|c|c|c|c|c|c|}
\hline RT-PCR & & & & & & & & & & & \\
\hline & & & & & Q vales & & & & SAR & $\mathrm{SCOV} 2 \mathrm{RT} \cdot \mathrm{PC}$ & RNit \\
\hline Dase of & attion & Sample tope & E & RAK & $\mathrm{x}$ & ORFiab & IC & interpnetatioe & Dereloper & $\begin{array}{c}\text { Nume of the } \\
\text { kit }\end{array}$ & Target Genes \\
\hline Apal & th & $\begin{array}{l}\text { Nooplungapea } \\
\text { ISwedb }\end{array}$ & . & * & 8.8 & 8.7 & 17.2 & $\begin{array}{l}2019-2 \mathrm{CoV} \text {. } \\
\text { Dreated. }\end{array}$ & $\begin{array}{l}\text { Certen linture } \\
\text { SI. }\end{array}$ & 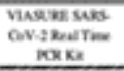 & Conat AN \\
\hline & 17t & 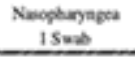 & . & * & . & $=$ & 20.2 & Nequive & & & \\
\hline Nargut & $\mathrm{ma}$ & 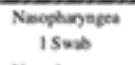 & & Renuly of & aned from molic & 4 Sitang & & $\begin{array}{l}\text { 2019-scoV } \\
\text { Desocied * }\end{array}$ & & & \\
\hline & 14at & $\begin{array}{l}\text { Nomphumagea } \\
\text { ismob }\end{array}$ & 16.13 & 2294 & 19.95 & . & . & $\begin{array}{c}2019.0 \mathrm{CoV} \\
\text { Datadid }\end{array}$ & & & \\
\hline & & stood & 2035 & 33.43 & 29.83 & - & 32.4 & $\begin{array}{l}\text { 2019-9cal } \\
\text { Detactod }\end{array}$ & & & \\
\hline & $\mathrm{seb}$ & Untase & . & $38 . n$ & 38 & . & 26.74 & $\begin{array}{c}2019-4 c 0 \mathrm{~V} \\
\text { Desteted }\end{array}$ & & & \\
\hline Spptentior & & Senew & $14 \%$ & 22.7 & - & & . & $\begin{array}{c}2019-4 \mathrm{coV} \\
\text { Detectod }\end{array}$ & Soregence abc. & $\begin{array}{l}\text { Allphex } 3019 . \\
\text { sCoV maxy }\end{array}$ & E. Rosp AN \\
\hline & 1th & $\begin{array}{l}\text { Nomplungagat } \\
\text { iswab }\end{array}$ & . & . & . & . & 24.34 & Nequive & & & \\
\hline & $25 \mathrm{st}$ & 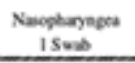 & . & . & 38.09 & . & 250 & $\begin{array}{c}2019-9 c \text { ov } \\
\text { Detectod }\end{array}$ & & & \\
\hline & & Shiod & $\cdot$ & " & $\cdot$ & . & 32.8 & Nequive & & & \\
\hline & sth & Whane & . & . & . & . & 9.as & Neystive & & & \\
\hline Oatuotar & & Senem & . & . & . & - & 25.61 & Nequive & & & \\
\hline & sat & $\begin{array}{l}\text { Nacophingneat } \\
\text { iswob. }\end{array}$ & . & . & . & & 25.86 & Nequive & & & \\
\hline & 160 & colssogyest & $\ldots$ & - &. & . & 2505 & Neruive & & & \\
\hline $\begin{array}{l}\text { Smamples selo } \\
\text { SEROLOGiC }\end{array}$ & TESTs & we listeres prepun & 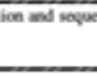 & & & & & & & & \\
\hline Simpledte & & Teat Tye & 幽 & 0 & Reflemene vales & & & & & & \\
\hline Septemitat & tat & Chemiluninesc 5 & & 0.41 & Reative $>1$ & & & & & & \\
\hline & & EISA & & $1.9 x$ & Rextive $>1$ & & & & & & \\
\hline Oatodert & sis & EISA & & 200 & Reative $>1$ & & & & & & \\
\hline & 160 & EISA & & 2.49 & Rentives! & & & & & & \\
\hline DILAMMII & $Y$ Bnos & RKERS & & & & & & & & & \\
\hline $5 \mathrm{mex}$ & & Fertitin & $\begin{array}{l}\text { CReative } \\
\text { Prosein }\end{array}$ & betrout & $.6(1.6)$ & & & & & & \\
\hline Avesest & 130 & 2257 & 42.18 & 202 & & & & & & & \\
\hline Siptenber & th & $37 \mathrm{~ns}$ & 3.33 & 2.75 & & & & & & & \\
\hline Oatober & $160 \mathrm{~h}$ & 236.7 & 304 & $\leq 15$ & & & & & & & \\
\hline & & 22.275 & 0.5 & 0.65 & $\begin{array}{l}\text { Relinence } \\
\text { valuess }\end{array}$ & & & & & & \\
\hline
\end{tabular}

\section{Figures}




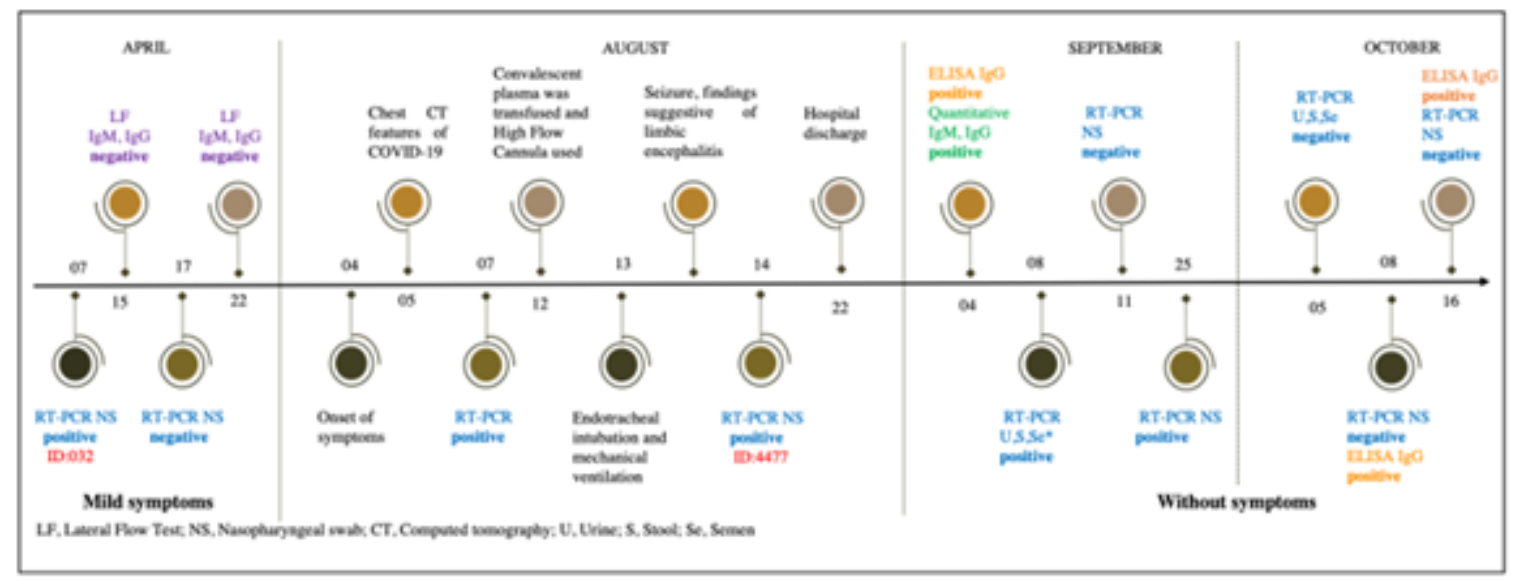

Figure 1

Timeline of the infectious process by SARS-CoV-2; clinical, serological and RT-PCR diagnostic tests performed during April and October 2020. Samples with ID:032 and 4477 were selected for Nanopore sequencing.

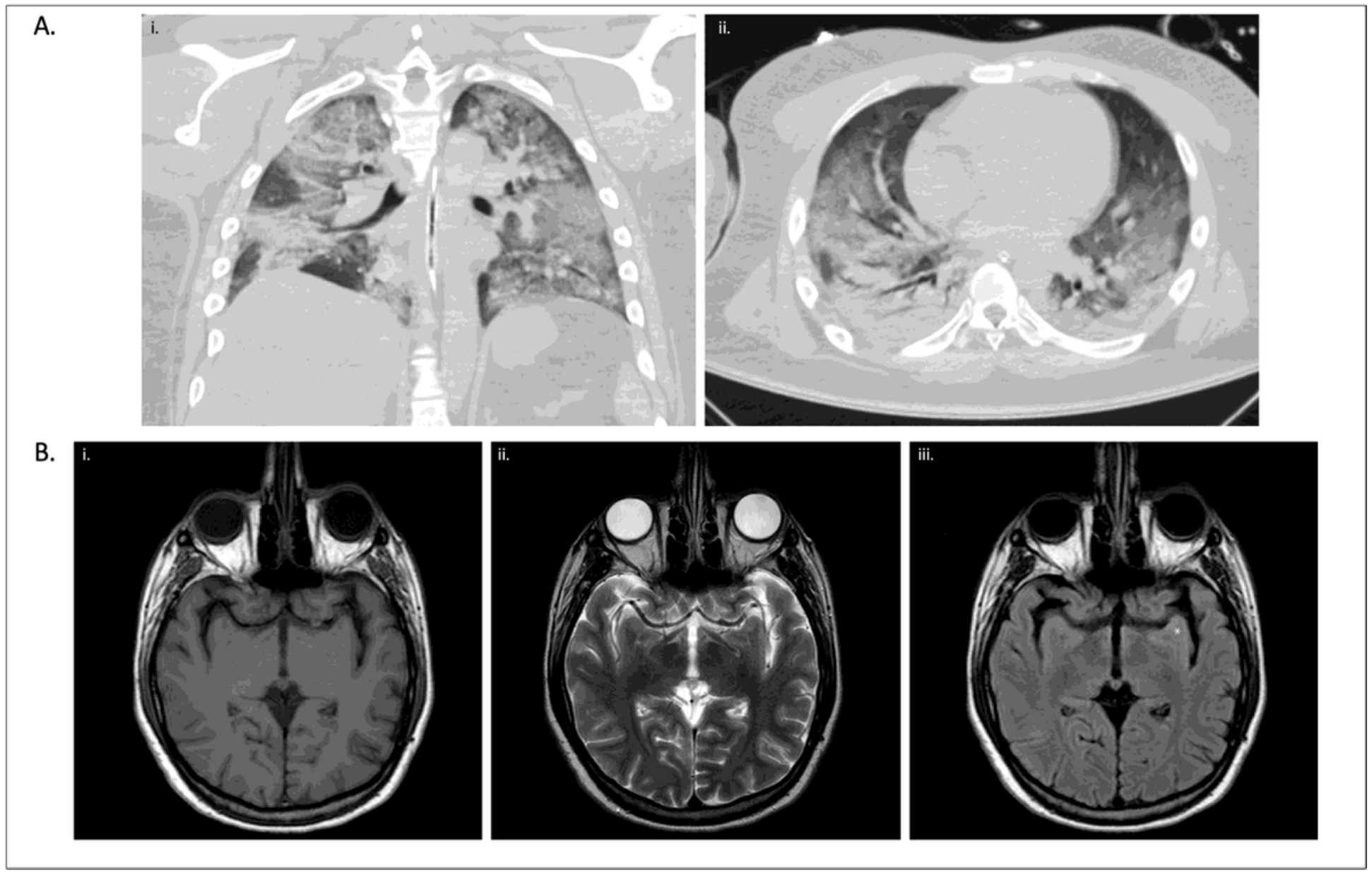

Figure 2 
A) Chest computed tomography (CT) revealed ground-glass opacities and consolidations at both lung bases in both lungs Compatible with pulmonary infectious process $i$ : coronal lung, ii: axial lung. B) Axial MR imaging scans the brain of a 35-year-old man intubated with COVID-19 i:T1, ii: T2, iii: T2-FLAIR . ( $\left.{ }^{*}\right)$ Reported as limbic encephalitis evidence.

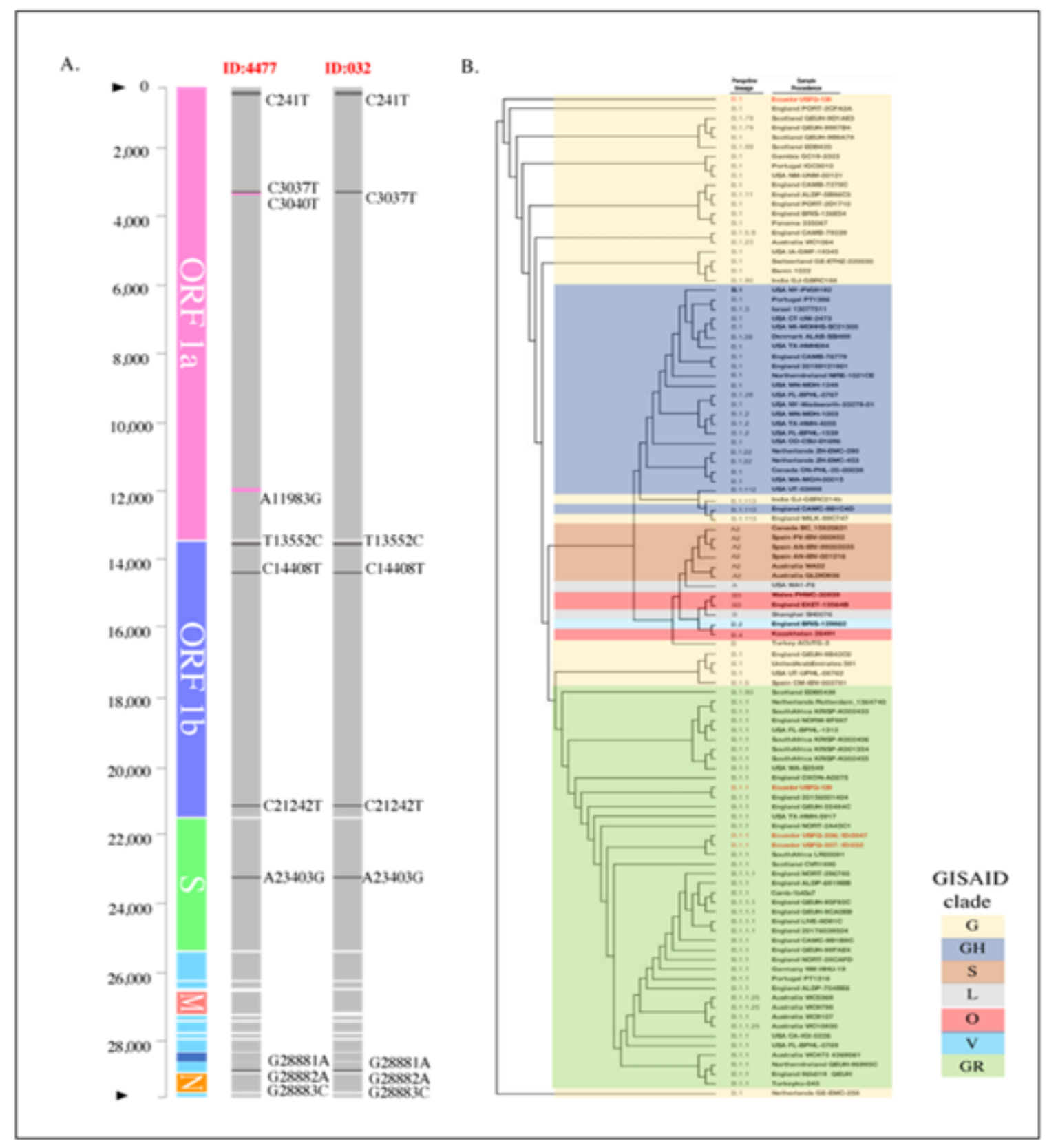

\section{Figure 3}

A) Single Nucleotide Polymorphism of the sequenced SARS-CoV-2 genomes diagnosed by RT-PCR in April (ID: 032) and August (ID: 4477). B) Maximum-likelihood phylogeny of one hundred subsampled SARSCoV-2 genomes from GISAID website. The columns refer to Pangolin lineage and sample precedence respectively, the colors correspond to which GISAID clade are the genomes related to. 